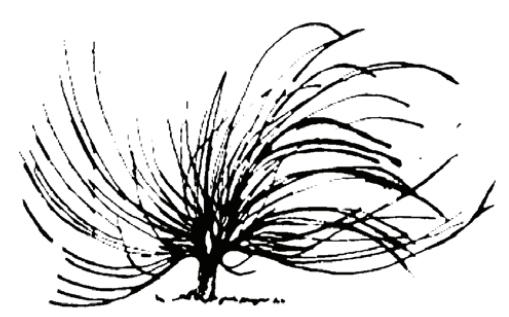

\title{
La Construcción Cultural del Currículo: Reflexiones en Clave Latinoamericana
}

\author{
Andrés Mora Ramírez ${ }^{1}$ \\ Universidad Nacional \\ Heredia, Costa Rica \\ andres.mora.ramirez@una.cr
}

\begin{abstract}
Resumen
En este ensayo se presentan una serie de aproximaciones teóricas y conceptuales al problema de la construcción cultural del currículo, con especial interés en las tensiones, tendencias, omisiones y vacíos que operan en el desarrollo curricular latinoamericano. Estas reflexiones han sido elaboradas a partir de una revisión del estado de la cuestión en la bibliografía especializada, lo que permitió un acercamiento dialéctico a los planteamientos de autores que, desde diversos campos del pensamiento crítico latinoamericano, aportan elementos para realizar un ejercicio de síntesis interpretativa.
\end{abstract}

Palabras clave: currículo, cultura, ideología, educación, pedagogía, pensamiento latinoamericano

\section{Abstract}

This essay develops a number of theoretical and conceptual approaches to the problem of the cultural construction of the curriculum in Latin American. It emphasizes

\section{(요요 $\Theta \Theta$}

Recibido: 28 de abril de 2015 - Aprobado: 18 de agosto de 2015

1 Profesor e investigador en el Instituto de Estudios Latinoamericanos y el Centro de Investigación y Docencia en Educación - División de Educología, ambas instancias de la Universidad Nacional (UNA). Magíster en Estudios Latinoamericanos con énfasis en Cultura y Desarrollo y Magíster en Educación con énfasis en Docencia Universitaria, títulos obtenidos en la UNA. 
the tensions, trends, omissions and gaps underlying its development. These reflections were developed based on a revision of the state-of-the-art literature which allowed a dialectal approach to the thoughts held by the authors. The critical thinking of these Latin American writers provided significant elements for this interpretative analysis.

Keywords: curriculum, culture, ideology, education, Latin American thinking

\section{Introducción}

La última década del siglo XX es reconocida por la literatura especializada en las ciencias sociales como el período de aplicación más férrea de las políticas neoliberales o neoconservadoras en América Latina. Bajo el ropaje de los llamados programas de ajuste estructural, se llevaron a cabo severas reformas institucionales, legales y económicas, con repercusiones innegables en el orden de la cultura, que transformaron los sistemas estatales latinoamericanos y, en no pocos casos, desataron profundas crisis sociales y escenarios de inestabilidad crónica que están en el centro de los actuales procesos políticos en la región.

Una nueva utopía, la modernización de las sociedades latinoamericanas por la vía del mercado (como institución reguladora de los procesos sociales), se instaló como horizonte ideológico de la clase política y la tecnocracia desde los años 1990. En el ámbito de la educación, campo cultural de disputa y construcción de sentido por excelencia, los organismos financieros internacionales emblemas del neoliberalismo -como el Banco Mundial y el Fondo Monetario Internacional- impulsaron ambiciosas reformas educativas, que involucraron desde el otorgamiento de empréstitos a los Estados para el financiamiento de infraestructura, hasta una activa participación en el diseño de políticas curriculares en todos los niveles del sistema educativo, especialmente en la educación superior: todo esto, con el objetivo de formar capital humano más productivo y de reorientar todo el quehacer educativo, incluida la profesionalización de la docencia, en función de los requerimientos que la nueva economía globalizada impone a las sociedades y a las economías nacionales. Salvo Cuba, por razones conocidas, no hubo 
un solo país de América Latina y el Caribe que permaneciera ajeno al influjo de esas transformaciones ${ }^{2}$.

$\mathrm{Si}$, como explica Joao Pareskeva (2008), el currículo es susceptible de ser leído y analizado como un discurso que define una práctica regulada de poder y como un campo cultural significativo, marcado por disputas, conflictos, negociaciones y propuestas para todos los actores del proceso educativo, entonces, cabe plantearse algunas preguntas: ¿Qué implicaciones tuvo la modernización educativa neoliberal en el ámbito curricular? ¿Cuáles han sido los supuestos epistemológicos, filosóficos y pedagógicos explícitos e implícitos -las racionalidades curriculares- que han acompañado estas transformaciones, algunas de las cuales todavía tienen plena vigencia en las universidades públicas y en el sistema educativo costarricense? ¿Sería posible avanzar por caminos alternativos, mucho más cercanos a nuestros referentes latinoamericanos, en el complejo proceso de construcción de los diseños curriculares como dispositivos culturales?

En este ensayo, se presentan una serie de aproximaciones teóricas y conceptuales a esa problemática: las tensiones, tendencias, omisiones y vacíos que operan en el desarrollo curricular latinoamericano. Tales reflexiones han sido elaboradas a partir de una revisión del estado de la cuestión en la bibliografía especializada, lo que permitió un acercamiento dialéctico a los planteamientos de autores que, desde diversos campos del saber crítico, aportan elementos para realizar un ejercicio de síntesis interpretativa.

Cabe puntualizar que dicho análisis se propone desde una perspectiva teórica construida en diálogo permanente con referentes de la filosofía y la pedagogía latinoamericana. De especial importancia fueron las ideas del filósofo argentino Arturo Roig (2009 y 2011), sobre la constitución del sujeto plural histórico latinoamericano, punto de partida para la creación de un pensamiento pedagógico propio, es decir, fundado y situado en nuestra específica realidad cultural; y del filósofo chileno Hugo Zemelman (2005), con sus ideas acerca del sujeto, su historicidad y la importancia del pensamiento propio en el paradigma crítico. Asimismo, en el campo pedagógico, consideramos las contribuciones recientes del

2 Autores como Saxe (2001), Cuevas (2008), Vargas (2008), Solano (2010) y Vega-Carballo et al. (2010) presentan un completo cuadro de lo ocurrido con la educación superior pública de América Latina y Costa Rica en las últimas dos décadas. 
investigador chileno Rolando Pinto (2008 y 2012) en el desarrollo de una teoría del currículo crítico y de la pedagogía transformativa.

Un aspecto clave que animó esta experiencia de escritura y construcción de conocimiento fue mi vivencia, primero como estudiante y luego como profesor, en el posgrado en Educación con énfasis en Docencia Universitaria de la Universidad Nacional (UNA), y las consideraciones en torno a lo que, en ese caminar, he advertido como la ausencia de enfoques teóricos y ejes curriculares fundados en la tradición y las innovaciones pedagógicas nuestroamericanas. Esta situación engarza con una de las principales tesis del sociólogo portugués Boaventura de Sousa Santos, quien en su crítica de las limitaciones epistemológicas de la razón dominante en el pensamiento occidental moderno, acuña la noción de mecanismos de producción de las ausencias para mostrar que lo que no existe -en términos de los discursos formales de las disciplinas científicas- "es producido activamente como no existente, como una alternativa no creíble, como una alternativa descartable, invisible a la realidad hegemónica del mundo" (Sousa, 2006, p. 23).

Como explica Sousa Santos, los modos de producción de las ausencias en las ciencias sociales, en particular, la monocultura del saber y el rigor (cuyo supuesto es que el único conocimiento científico válido es el que proviene del Occidente desarrollado), y la monocultura del tiempo lineal (que asume que todo lo que existe en los países desarrollados es más avanzado y progresista que lo que existe en los países falsamente llamados subdesarrollados), se reproducen en la tendencia a trasladar a nuestros contextos, sin mayor juicio crítico que la pretendida autoridad de ser productos metropolitanos, los resultados de investigaciones y esfuerzos de sistematización teórica construidos en escenarios sociales, culturales, económicos e ideológicos sustancialmente diferentes a los de nuestro contexto regional latinoamericano. Una práctica en la que incurrimos -consciente o inconscientemente- cuando aplicamos en nuestras investigaciones marcos teóricos y categorías analíticas que, en general, no superan los horizontes definidos por la ciencia y la literatura del Norte dominante en la geopolítica del conocimiento; y en la que se expresa el peso de las concepciones ideológicas hegemónicas, tanto en la sociedad, como en el sistema educativo.

Parto de una premisa: toda propuesta curricular es un recorte de saberes, una selección de determinados contenidos en la que actúan aspectos ideológicos, políticos y culturales, que acaban por reducir la diversidad 
de la realidad, del conocimiento y, por lo tanto, de las potencialidades del ser docente, ajustándolas a los intereses hegemónicos de una comunidad educativa, en un tiempo y en un lugar determinados de su historia.

Es decir, las preguntas sobre el porqué, el para qué y el cómo del currículo y sus contenidos, sus principios y sus prácticas, finalmente nos llevan a interrogarnos sobre cómo existimos en el mundo de la producción y legitimación de los conocimientos y los saberes. Y en nuestro caso concreto, nos emplazan sobre los rumbos e intencionalidades de la formación docente en la UNA, en particular, y en la educación superior costarricense, en general.

\section{Hegemonía, contrahegemonía y tensiones curriculares en la formación docente en América Latina}

En general, los procesos de construcción cultural del currículo, y dentro de esto, la incorporación de la perspectiva pedagógica latinoamericana y caribeña, han sido poco abordados en la literatura especializada. A nivel nacional, no se localizaron estudios que problematicen la intencionalidad ideológica, las opciones que se hacen por unos específicos principios filosóficos y epistemológicos, ni los referentes culturales presentes en los diseños curriculares de los programas universitarios. En el plano internacional, la mayoría de los estudios relacionados se orientan hacia aspectos como la evaluación de la formación docente (Vain, 1998; Fernández y Coppola, 2008), los procesos de organización institucional de la formación en docencia (Pestana, 2003), la formación por competencias del profesorado universitario y otras prácticas innovadoras (Lucare1li, 2004; González y González, 2008; Barrón, 2009), e incluso hacia la responsabilidad ético-científica del docente (Soto, 2009).

No obstante, también es posible afirmar que en la última década y media se aprecia un creciente interés por investigar la formación docente en América Latina y su relación con las políticas curriculares, la construcción del currículo y el contexto socioeconómico y cultural en que este se pretende desarrollar; temas que son abordados en clave latinoamericana desde la pedagogía crítica. Así, por ejemplo, a inicios del presente siglo, Duhalde y Cardelli (2001) elaboraron un diagnóstico sobre los aspectos críticos de la formación docente en América Latina, en el que prestaron atención a las presiones y regulaciones impuestas por los sistemas económicos y políticos neoliberales sobre "la cultura 
de las instituciones de formación docente, el trabajo docente y el desarrollo curricular" (p. 39).

Sus principales hallazgos conservan vigencia como marco referencial de las problemáticas de la formación del profesorado que no son ajenas al contexto costarricense, y mucho menos de la UNA. Así, por ejemplo, identifican dificultades para la constitución de comunidades y colectivos docentes, "ya que se impulsa el trabajo aislado, fragmentario y en soledad, impidiendo todo proceso de reflexión que permita construir propuestas alternativas conjuntas, en relación con la propia práctica". Además, la imposición de políticas educativas economicistas, y su correlato en la "fragmentación entre las propias instituciones de formación docente, evitando la construcción de una identidad del conjunto y como organización colectiva, donde se pueda desarrollar una horizontalidad para la discusión y la elaboración de alternativas de transformación" y desde el punto de vista curricular, identificaron instituciones de formación docente con una débil relación con la realidad sociocultural circundante y estructuras curriculares relativamente invariantes "donde las disciplinas siguen siendo el eje del currículo", y donde a la investigación se le sigue considerando "como una asignatura o área, antes que como una metodología permanente y transversal en el desarrollo curricular" (Duhalde y Cardelli, 2001, p. 39-40).

En las conclusiones de su informe, estos autores establecen que en nuestra región la formación docente se caracteriza por su énfasis instrumental, "pues se encamina hacia la preparación del educador como técnico y operador". Además, señalan que el desarrollo curricular latinoamericano, fuertemente centralizado, tiende a "negar la experiencia previa y el conocimiento de los educadores", a desentenderse de "las condiciones reales y las particularidades de cada contexto" educativo y a enfatizar "en el conocimiento de tipo académico y teoricista, despreciándose la práctica educativa como la fuente más importante que tienen los educadores para continuar aprendiendo y producir nuevos conocimientos acerca de misma" (Duhalde y Cardelli, 2001, p. 42).

En un trabajo posterior, Duhalde (2008, p. 202) propone que un posible camino para superar parte de esas condiciones adversas es el que sugieren los planteamientos de la pedagogía crítica latinoamericana -en particular las ideas de Paulo Freire-, toda vez que permiten resituar la tarea docente no como una simple transmisión de contenidos ni "como una regla técnica o un mecanismo rígido y exacto", sino 
como un desafío de formación humana plena que "radica en enseñar y aprender a pensar correctamente". En este sentido, y sin perder de vista el peso normativo del sistema educativo, y sus relaciones de poder intrínsecas, el autor considera que la formación docente debe reorientarse a partir de cuatro ejes o pilares:

- $\quad$ El de la concepción del conocimiento como "construcción que es posible a partir del diálogo" (Duhalde, 2008, p. 207) entre educadores y educandos, por lo tanto, se opone a las concepciones bancarias del conocimiento, afines a la visión instrumental de la educación y la docencia.

- $\quad$ El respeto por los saberes del educando, que no pueden aislarse o marginarse del proceso educativo, pues se reduciría la docencia a un "puro adiestramiento técnico" que negaría, a su vez, "el reconocimiento de la autonomía de las personas" (Duhalde, 2008, p. 208).

- El estímulo de la curiosidad creativa y la investigación, lo que supone "preparar al profesor para comprender la realidad educativa y tener una actitud experimental con relación a dicha práctica", es decir, se trata de profundizar la dimensión dialéctica de la pedagogía, que "se basa en la preparación de los educandos y educadores para ser pensadores críticos y sujetos capaces de participar en la creación de procesos de investigación, por ende, conocer el mundo para transformarlo" (Duhalde, 2008, p. 210).

- La reflexión crítica sobre la práctica como proceso permanente y acción indispensable en la formación docente "no sólo para modificar la práctica a partir del pensamiento, sino para generar nuevos pensamientos a partir de la práctica", así como para estimular la curiosidad epistemológica del futuro docente y "el reconocimiento de una identidad cultural que también está atravesada por lo emocional" (Duhalde, 2008, p. 211).

En esta misma línea, y a partir del análisis del caso venezolano, Olmos (2008, p. 157) propone incorporar la pedagogía crítica "como eje y fundamento de la formación docente"; más aún, considera que esta es una condición sine qua non para avanzar hacia el diseño y desarrollo curricular "inspirado en principios pedagógicos que responden a las características históricas, sociales, políticas, económicas, culturales de la población a la cual se dirige, en atención a los cambios que se 
generan en ella". De acuerdo con esta autora, los principios de la pedagogía crítica, a saber, la relación entre teoría y práctica, la racionalidad crítica dialéctica, la contextualización, la investigación-acción deliberativa y colaborativa, y la finalidad ética, pueden ser determinantes en la construcción de diseños curriculares que procuren una visión integral y global de la formación docente.

Para Olmos (2008, p. 169), un enfoque pedagógico y curricular de esta naturaleza permitiría avanzar hacia una ruptura con el paradigma dominante de formación, que da preeminencia a la dimensión técnica de la docencia, cuya principal expresión se observa en el desplazamiento de la práctica reflexiva y crítica para privilegiar "la planificación con objetivos observables o competencias (conocimientos, habilidades y actitudes), contenidos predeterminados y evaluación centrada en la medición de resultados preestablecidos".

En apoyo de estas tesis, Becerra y Moya (2009) también abogan por la recuperación del pensamiento educativo y pedagógico latinoamericano, al que vislumbran irremediablemente unido a los procesos de transformación social, incluida aquí la superación de los lastres culturales y epistemológicos que se arrastran desde el siglo XIX. Es decir, reivindican que el Sur, como categoría histórica y sociocultural que define a los pueblos latinoamericanos, empiece a mirarse y a pensarse desde el Sur. Se trata, pues, de una posición ética que define un eje axiológico constitutivo de lo que en este ensayo entiendo como la perspectiva pedagógica latinoamericana y caribeña.

Como explican los autores, contamos con suficientes elementos para construir "una visión latinoamericana sobre la base de nuestros pensadores que dieron pautas para una construcción crítica de la didáctica y la pedagogía, comprometida con amplios sectores de la población, que tradicionalmente fueron y son excluidos" (Becerra y Moya, 2009 , p. 19). Ese rescate del pensamiento pedagógico latinoamericano es indispensable para desarrollar nuevas dinámicas y prácticas pedagógicas en las aulas durante la formación de los docentes; prácticas y dinámicas que enfaticen "la construcción y reelaboración de los conceptos", la resolución de problemas, la observación, la investigación acción, los aprendizajes cooperativos, la capacidad de argumentación y los estilos pedagógicos democráticos y liberadores (Becerra y Moya, 2009, p. 20-21). 
Por otra parte, en términos de las investigaciones sobre el currículo, se encontró una tendencia historiográfica que prioriza la caracterización del desarrollo de las teorías curriculares en América Latina (Mora, 2004); una tendencia mucho más orientada al desarrollo teórico y empírico del currículo crítico en América Latina y al estudio de los aportes del pensamiento pedagógico latinoamericano en este ámbito. De esta última, destaca el trabajo de Guzmán y Pinto (2004), quienes proponen como tesis la necesidad de una ruptura con los marcos tradicionales (instrumentales) de elaboración y producción del currículo y consideran que la vía para lograr esta superación pasa por asumir el enfoque "epistemológico socioconstruccionista, que concibe el conocimiento como un sentido/significado relacional entre el sujeto y su entorno sociocultural y físico".

De esta forma, su concepción del currículo -y de su proceso de construcción- va más allá de la prescripción de contenidos por parte de las autoridades educativas de un centro académico o una agencia o ministerio estatal, en cambio, lo consideran como el resultado de una experiencia de acción y comunicación crítica transformadora de los sujetos de la comunidad educativa. El proyecto curricular, en tanto proyecto cultural, "es el producto colectivo institucional de una práctica social de búsqueda de sentidos y de significados para una comunidad escolar situada" (Guzmán y Pinto, 2004, p. 126).

En estudios posteriores, Pinto (2009) profundiza en su línea de investigación y afirma que el espacio educativo, en sus distintos, debe ser entendido como espacio de inclusión sensible a todas aquellas temáticas, demandas, movimientos socioculturales y problemáticas que emergen de las dinámicas sociales latinoamericanas, y de su propia diversidad cultural y geográfica, que hoy son producidas sistemáticamente como ausencias -al decir de Boaventura de Sousa- en los diseños y constructos curriculares.

Además, Pinto (2009, pp. 6-7) formula una crítica al paradigma técnico/instrumental del currículo y a su modelo centrado en la enseñanza homegenizante; en particular, cuestiona y debate tres de los supuestos teóricos principales de este paradigma, a saber:

- Que el currículo debe ser diseñado por técnicos y expertos políticos, lo que implica aceptar y legitimar, a su vez, la existencia de grupos que poseen y dominan los saberes pedagógicos, y su 
manera de organizar dichos conocimientos es la única posible en un sistema educativo.

- $\quad$ El fuerte sentido ideologizante que acompaña a la definición, por parte de esos técnicos y expertos, de "los objetivos fundamentales y los contenidos mínimos obligatorios" del currículo, lo que degenera en una cultura escolar hegemónica, monocultural, unidimensional, "iluminista" y eurocentrista.

- $\quad$ La idea de que los docentes conocen y aplican -sin más- los códigos didácticos y pedagógicos que el currículo oficial define para cada disciplina, supuesto este que anula las posibilidades de innovación y de adecuación del currículo a las realidades históricas, culturales, sociales y políticas de cada contexto educativo.

A partir de esto, elabora una propuesta centrada en el análisis de las realidades educativas latinoamericanas y en el protagonismo del educando, como oposición al currículo basado simplemente en la enseñanza, es decir, en la idea de la transmisión de conocimientos y la reproducción de la cultura oficial. Pinto (2009, pp. 11-12) integra elementos de las teorías del currículo crítico-transformativo y del currículo como acción comunicativa y organiza su perspectiva en torno a tres ejes:

1. El análisis del ser y estar en América Latina, en sus dimensiones antropológica e histórico-situacional, como punto de partida para la innovación educativa y curricular crítica.

2. La multiculturalidad latinoamericana (en términos de sus lenguajes, historias, tradiciones, entornos sociales) como sentido humanizante y orientador "para la selección, organización y gestión de la cultura y el currículo escolar latinoamericano".

3. La opción por una pedagogía crítica de lo humano, basada en la construcción participativa y en la vinculación efectiva con las realidades locales y nacionales que demandan ser transformadas.

Más recientemente, Pinto (2012) ahonda en las relaciones entre pensamiento filosófico y pedagógico latinoamericano y su visión crítica del desarrollo curricular para la formación docente. Así, aborda la cuestión del sujeto socioepistémico en la educación en América Latina, lo que involucra los perfiles deseables tanto del docente como de los estudiantes en el proceso de construcción de actores ontológicamente situados, 
conscientes de su territorialidad geográfica y cultural, y de sus interconexiones e interacciones sociales (Pinto, 2012, p. 33). Esta caracterización la realiza desde una perspectiva multidisciplinaria, que incluye aportes de la filosofía, las ciencias sociales y la pedagogía crítica latinoamericana (por ejemplo, de intelectuales como Augusto Salazar Bondy, Enrique Dussel, Edgardo Lander, Paulo Freire y Hugo Zemelman).

El investigador chileno también presenta un conjunto de ideas con respecto al conocimiento en la acción educativa (cómo se realiza, cuáles son sus fuentes epistemológicas, cuáles teorías orientan la comprensión del fenómeno, etc.) y, luego, hace lo propio con lo que llama "sentidos ético-sociales y políticos" de las prácticas educativas. Estos se identifican como alternativas del docente latinoamericano y, si cabe la expresión, como sus opciones preferenciales si se tiene como horizonte la transformación de la realidad inmediata de la comunidad educativa, de la comunidad local y nacional.

Además, Pinto se refiere a los saberes pedagógicos que, desde su perspectiva, deberían acompañar la práctica pedagógica y didáctica de los docentes latinoamericanos situados en su realidad social, en la diversidad cultural de nuestras naciones, y en nuestra especificidad histórica. Para efectos de nuestro ensayo, resulta fundamental la afirmación de que en América Latina:

(...) necesitamos legitimar una mirada sobre estos principios [filosóficos y epistemológicos], que fundamentan la práctica formativa, pero, esta vez, desde la historia, las identidades socio-culturales, las tradiciones ético-políticas y pedagógicas que nos constituyen como territorios latinoamericanos. Solo desde ese rescate de lo propio podríamos entender las condiciones teóricas y políticas que nos impiden avanzar en el desarrollo de una educación propia, que dé más calidad a los procesos y productos formativos que desarrollamos con nuestras prácticas formativas. (Pinto, 2012, p. 15)

Muy cercanos a los planteamientos de Pinto, encontramos que Acosta et al. (2010, p. 33), a partir de la revisión de los fundamentos históricos, epistemológicos y teóricos de la pedagogía crítica latinoamericana, indagan sobre el currículo sociocrítico y lo definen como aquel en que el educando "participa activamente en su formación" y 
en el que asume "un compromiso con los contenidos curriculares nacido de esa participación". Como explican estos investigadores, el currículo sociocrítico se inscribe en un paradigma transformativo de las relaciones de poder y las desigualdades propias de toda formación social. Desde esta perspectiva, el currículo se concibe como posibilidad de transformación, como "una instancia para reconstruir la sociedad, para actuar sobre ella, contribuyendo decididamente a la solución de problemas que la afectan". Esto supone, entonces, un enfrentamiento con las visiones paradigmáticas y las corrientes teóricas hegemónicas en el campo curricular latinoamericano, donde "los temas del poder y el control quedan marginados así como los conflictos y los mecanismos de resistencia que existen en la relación educación y sociedad" (Acosta et al., 2010, p. 36-37).

Todo lo expuesto hasta aquí confirma que en América Latina se empieza a perfilar una preocupación, al menos en los círculos intelectuales y entre investigadores de la educación, por trascender las concepciones curriculares -o racionalidades curriculares, como las entiende Pinto (2008)- dominantes en los sistemas educativos nacionales, y que resultan funcionales al modelo económico, político y cultural todavía hegemónico en muchos de nuestros países: el neoliberalismo. Estos esfuerzos, tanto en lo que se refiere a establecer líneas de investigación y de producción teórica, como a la identificación de problemáticas en la formación de docentes universitarios, apuntan hacia el imperativo de revisar y replantear los procesos de construcción del currículo, al mismo tiempo, de incorporar principios, valores y enfoques situados en la realidad latinoamericana.

\section{La construcción del currículo en perspectiva crítica}

Cuando afirmamos que el currículo es una construcción cultural e ideológica, en la que es posible hacer una lectura crítica de las visiones de mundo, de los principios filosóficos y epistemológicos que lo sustentan, $\mathrm{y}$ de las concepciones pedagógicas hegemónicas en una comunidad educativa, en un momento y un lugar determinados, lo que pretendemos enfatizar es su condición de campo complejo, sometido a tensiones creativas -y también restrictivas- de naturalezas tan disímiles como sujetos e intereses se expresan en una sociedad. El reconocimiento de las mediaciones que existen en torno al currículo, y que en no pocos casos 
acaban por imponerse en su proceso de diseño e implementación en el aula y en la institución educativa, es abordado por distintos autores con matices más o menos problematizadores.

Desde la teoría crítica de la educación, por ejemplo, en Ideología y currículo, la obra clásica del estadounidense Michael Apple (2008), publicada por primera vez a finales de la década de 1970, encontramos postulados que sustentan nuestro interés por desarrollar un análisis centrado en las dimensiones ideológicas y culturales de la construcción curricular en la educación superior. Apple cuestiona, por insuficiente, la tendencia tecnológica y programática dominante en el estudio del currículo, en cambio, reivindica una aproximación al problema del conocimiento educativo -qué es, cómo se organiza y almacena, cómo se enseña y sistematiza en un currículo- desde la ideología, lo que permitiría desentrañar los sentidos que subyacen a los procesos de construcción del conocimiento legitimado por determinados grupos y clases sociales.

Apple nutre sus puntos de vista de la perspectiva neomarxista y plantea como preocupaciones centrales de la investigación sobre el currículo las relaciones de poder-mediadas por las disputas ideológicas y las luchas por el control de los recursos- al interior de una formación social y de sus instituciones productoras y reproductoras de cultura. En su criterio, el currículo, por su propia naturaleza y por estar inscrito en los parámetros de la escuela en el sistema moderno/capitalista, responde a y representa los recursos ideológicos y culturales de unos grupos, en detrimento de otros. La ideología, entonces, ejerce una influencia decisiva en la configuración curricular de los procesos educativos y formativos:

Las formas de conocimiento (tanto público como encubierto) que encontramos dentro del marco escolar implican nociones de poder y control de recursos económicos. La propia elección del conocimiento escolar, el acto de diseñar entornos escolares, aunque puede no hacerse conscientemente se basa a menudo en presuposiciones ideológicas y económicas que proporcionan las reglas lógicas para el pensamiento y la acción de los educadores. (Apple, 2008, p. 67)

El teórico estadounidense va aún más lejos en su develamiento del carácter conflictivo del currículo, y apunta a lo que podríamos llamar como un vínculo de origen entre la escuela como institución, la selección del conocimiento legitimado y el control social: 
(...) el campo curricular tiene sus raíces en el suelo del control social. Su paradigma intelectual tomó forma primeramente en la primera parte de este siglo [siglo XX], convirtiéndose en una serie identificable de procedimientos de selección y organización del conocimiento escolar; procedimientos que han de ser enseñados a los profesores y demás educadores. En aquel tiempo, el interés fundamental de las personas del campo de currículo era el del control social. (Apple, 2008, p. 68)

También desde la perspectiva crítica, pero en un enfoque mucho más anclado al pensamiento pedagógico latinoamericano, Pinto (2008) se refiere a dos maneras de comprender el currículo: la primera, propia del paradigma histórico-crítico de la educación, lo concibe como "un proceso de enmarcamiento del educando de acuerdo con ciertos códigos seleccionados y clasificados como necesarios para el desarrollo psicosocial y cultural" (p. 98); como se ve, nuevamente aparece aquí la idea de orientación y control de los sentidos y significados culturales, sobre "la intencionalidad sistémica y ético-social de la educación", tarea que en América Latina, tradicionalmente, ha sido asumida por aquellos segmentos tecnocráticos de los grupos dominantes "que poseen una capacidad argumentativa e intelectual orientada a la funcionalidad de la educación al modelo capitalista" (p. 98).

Por el contrario, la segunda forma de concebir el currículo a la que hace referencia Pinto, pone en la reflexión un horizonte de posibilidades de transformación, de cambio social y cultural. Según este autor, tanto la pedagogía como el currículo son portadores de contenidos y prácticas emancipadoras, que podrían propiciar una "ruptura con la tradición cognoscitiva-prescriptiva de la cultura, a la vez, la integración de la diversidad multicultural" (p. 102) de los actores del sistema educativo. El investigador chileno amplía esta tesis al señalar que:

(...) si la actividad formativa es, principalmente, una acción de seleccionar y organizar los sentidos, los significados, los contenidos culturales, ella no puede limitarse solo a la posibilidad de determinar conocimientos comunicables, sino que, en tanto aprendizajes efectivos, debieran generar en los educandos capacidades para reflexionar, interpretar, resignificar o inventar cualquier tipo de constructo cultural, que contribuya a la liberación en la vida concreta a cualquier manifestación de opresión cotidiana. (Pinto, 2008, p. 102) 
Tales preocupaciones sobre la cuestión curricular no son exclusivas de la escuela del pensamiento crítico. Desde otras corrientes teóricas y epistemológicas, encontramos planteamientos que también se emparentan con la visión del currículo como dispositivo cultural que tomamos como punto de partida. En ese sentido, nos interesa destacar tres conceptos propuestos por Gimeno-Sacristán (2010), quien entiende al currículo como una construcción discursiva, como una práctica regulada (y reguladora) de poder, por lo tanto, que expresa intencionalidades susceptibles de ser decodificadas e interpretadas en su contexto.

Uno de estos conceptos es el del currículo como instrumento regulador de los contenidos y saberes que caben en el diseño de un plan de estudios o de curso, por lo tanto, también norma las prácticas educativas y las prácticas intelectuales de los docentes; visto así, el currículo tiene un doble carácter de propuesta e imposición, toda vez que en su elaboración intervienen las instancias de autoridad del sistema y la comunidad educativa. Al respecto, Gimeno-Sacristán (2010) explica lo siguiente:

El currículo se nos presenta como una invención reguladora del contenido y de las prácticas implicadas en los procesos de enseñanza-aprendizaje; es decir, que se comporta como un instrumento que tiene capacidad para estructurar la escolarización, la vida de los centros educativos y las prácticas pedagógicas, pues dispone, transmite e impone reglas, normas y un orden que son determinantes. (p. 26)

Un segundo concepto relevante es el de la no neutralidad del currículo, lo que remite a su dimensión de campo cultural -en el sentido que el sociólogo Pierre Bordieu daba a esta noción-, en consecuencia, a ser comprendido como espacio de disputas simbólicas y de construcción de hegemonía (también de resistencias), en el que se expresan tensiones no solamente técnicas y metodológicas, sino fundamentalmente ideológicas (modelos de sociedad, opciones políticas, filosóficas, culturales). En este sentido, Gimeno-Sacristán (2010, p. 29) afirma que el currículo "no es algo neutro, universal e inamovible, sino un territorio controvertido y hasta conflictivo".

El tercer concepto es el del currículo como expresión de un proyecto cultural y educativo, que enmarca el quehacer de las instituciones y comunidades y orienta sus objetivos; por lo tanto, también 
expresa "fuerzas, intereses, valores y preferencias de la sociedad, de determinados sectores sociales, de las familias, de grupos políticos" (Gimeno-Sacristán, 2010, p. 30).

En un enfoque similar, que involucra las dimensiones social y política, Beltrán (2010) introduce tres dimensiones que deben ser consideradas en la comprensión del proceso de construcción cultural del currículo: una, las relaciones entre política y currículo, toda vez que los procesos de conformación de este último son espacios "privilegiados para que puedan cumplirse a través suyo acciones de poder" (Beltrán, 2010, p. 49). Aquí se enfrentarían intereses y visiones de los actores de la comunidad educativa universitaria y agentes externos. La otra dimensión se refiere al currículo y la legitimación de los saberes, pues en su elaboración y ejecución en el centro educativo y el aula, los conocimientos recién producidos o acumulados son sometidos a revisión, selección, ordenamiento y valoración, antes de ser puestos en circulación. Y la última, nos enfrenta al sentido del currículo en la cultura institucional, es decir, cuál es la función que desempeña el currículo en la escuela y en los procesos formativos y de socialización que allí se desarrollan.

Como se puede apreciar, en torno al currículo como constructo giran ideas y nociones tales como poder, campo cultural, control social, recorte de saberes, reproducción cultural, legitimación de conocimientos, o no neutralidad; no obstante, también reconocemos su potencial emancipador. Es que el currículo, como producto concreto de una intencionalidad educativa, puede explicitar contenidos y entrelazar prácticas en diversas direcciones. En ese sentido, el concepto de racionalidad curricular emerge recientemente para designar la manera de organizar los sentidos y factores curriculares (conocimientos disciplinares, asignaturas o áreas de aprendizaje, valores y actitudes, relaciones y comportamientos sociales, lenguajes, experiencias de mundo, entre otros). Con la noción de racionalidad curricular, explica Pinto (2008, p. 92), se pretende dar cuenta de la configuración del currículo como "campo intelectual que se construye según las opciones de poder, de saber y de hacer educativo que tienen los actores que deciden esa construcción". Es decir, que responde a las opciones paradigmáticas que elige y construye una agencia de política pública, un centro educativo, un programa formativo o un especialista del currículo.

Retomando aspectos de la teoría crítica, así como los aportes del filósofo Hugo Zemelman, Pinto (2008) profundiza en la caracterización 
de la idea de racionalidad: esta sería una realización subjetiva del individuo mediada por sus condiciones de pertenencia a un colectivo sociocultural, del que obtiene el sustrato ideológico de sus decisiones y opciones; además, afirma que las racionalidades "son acciones históricas que se expresan en el lenguaje, y en cuanto tales, orientaciones determinantes para el saber y el hacer" (p. 93) dentro de las dinámicas constitutivas de dicho colectivo.

En el caso concreto de América Latina, sería posible distinguir, al menos, cuatro grandes vertientes o expresiones a partir de las cuales se analiza el tema de las racionalidades curriculares. Una es la vertiente reproductora o adaptativa, también conocida como racionalidad técnico-instrumental, que varios autores identifican con aquellas posiciones y construcciones de los curriculistas que "reproducen adaptativamente los conceptos provenientes de los teóricos del currículo, casi todos de origen anglosajón, y a los cuales se agregan algunos españoles", quienes centran sus análisis en "el ámbito sistémico de la institución educativa", envuelto "en un discurso crítico-constructivista" (Pinto, 2008, p. 100101), que entienden la cuestión de los paradigmas como algo opcional, que puede ser asumido por el docente sin que esto comprometa los fundamentos filosóficos, axiológicos y pedagógicos de sus prácticas.

La segunda es la vertiente comprensiva: para esta racionalidad, el centro educativo, como espacio social, se convierte en punto de convergencia o, más precisamente, de "interacción comprensiva" entre los distintos actores y sus propios códigos culturales; es decir, retoma la concepción del currículo como campo cultural, en el que sujetos, experiencias y visiones de mundo y sociedad forjadas en distintos medios luchan $\mathrm{y}$, en el mejor de los casos, negocian los contenidos y significados que se desarrollan a través de los planes y programas de estudio. Como se desprende de lo anterior, en la vertiente del currículo comprensivo "la posibilidad de que el sujeto social construya su conciencia crítica, depende entonces de la calidad o el peso cultural que valida el currículo" (Pinto, 2008, p. 104) y del tipo de proyecto curricular que el educador sea capaz de poner en práctica con los educandos.

La vertiente crítica, tercera en este recuento, corresponde a la desarrollada por lo general por científicos y filósofos sociales, que propugnan una opción crítica y de denuncia del paradigma dominante en la educación latinoamericana, y la consecuente ruptura paradigmática con este modelo educativo y curricular para avanzar, entre otras cosas, hacia 
construcciones curriculares que procuren integrar la multiculturalidad, las manifestaciones que surgen desde lo popular y las prácticas pedagógicas alternativas. Para Pinto (2008, p. 101), si bien los exponentes de esta vertiente han logrado visibilizar como prioridad latinoamericana la necesidad de "rescatar la educación como posibilidad dialéctica de transformar el conocimiento en conciencia y en voluntad de acción de cambio de la realidad" regional, sus avances concretos dentro de los sistemas educativos han sido más bien discretos y continúan siendo experiencias alternativas valiosas, sí, pero de frontera, es decir, confinadas a una cierta marginalidad que impide la ampliación de sus efectos y sus hallazgos. No negamos que esta es una apreciación ajustada a la verdad en muchos aspectos, sin embargo, consideramos que el talante crítico visible en esta vertiente también es una condición imprescindible, dadas las herencias históricas y culturales que están en la raíz de la constitución de nuestras naciones, para repensar las dinámicas y los procesos que intervienen en la construcción del currículo en la educación latinoamericana.

Finalmente, la vertiente crítico-transformativa del currículo retoma elementos de la vertiente crítica pero, al mismo tiempo, intenta una superación de la simple denuncia de las desigualdades y las influencias hegemónicas que indudablemente permean las políticas curriculares, y se pregunta cómo incorporar e introducir prácticas reales de cambio en el sistema educativo latinoamericano. Pinto (2008), uno de sus principales impulsores teóricos, señala cuatro ejes para esta propuesta:

- La idea de que el currículo "no es solo transmisión de conocimientos, ni tampoco un simple modelo de construcción categorial de un sujeto social crítico moderno", a saber, un sujeto que solo produce "conocimientos científicos o lógico-intelectuales argumentativos" (p. 105).

- La importancia de que la acción comunicativa, gnoseológica y ontológica sea un pilar en el desarrollo del currículo, esto es, "entender el lenguaje, no solamente como expresión argumentativa de la constitución de la razón científica moderna, sino que sobre todo, como una acción transformativa, que re-posiciona como actor al sujeto en formación" (p. 106).

- La articulación de la multiculturalidad latinoamericana en el currículo, lo que supone la inclusión plena y efectiva de "los 
saberes, haceres y sentires" (p. 107) provenientes de los pueblos originarios, del mundo de las culturas locales comunitarias, de los movimientos socioculturales, así como los énfasis que adquieren en cada época los saberes disciplinarios universales, las motivaciones personales del sujeto en el aprendizaje escolar y los códigos científicos y tecnológicos más actuales.

- La necesidad de conceptualizar y desarrollar el currículo como "un proceso de reorganización del poder en el microclima organizacional y cultural de la institución educativa", como condición básica para dar paso a transformaciones mayores en los órdenes local-comunitario, nacional-social y regional-latinoamericano, orientados a ampliar los criterios formativos y pedagógicos más allá de lo estrictamente academicista, del autoritarismo y el elitismo curricular, y de "las prácticas normativas y la validación de parámetros puramente cognoscitivos en los procesos educativo-curriculares" (pp. 105-110).

Si bien toda generalización implica un sesgo reduccionista, casi inevitable, consideramos que esta sistematización o esquema de las tendencias curriculares presentes en América Latina resulta de gran utilidad para los propósitos de este ensayo. Asimismo, nos interesa destacar una tesis clave del investigador chileno, por cuanto justifica el uso del enfoque de las racionalidades y vincula esta categoría con los argumentos que expusimos antes en torno al currículo y la ideología:

(...) en la construcción curricular, hay opciones posibles para la selección y organización del contenido curricular, lo que supone que al decidir sobre estas opciones, sus actores asumen compromisos con sentidos de vida y con relaciones de poder y de saber-hacer que configuran verdaderos campos de fuerzas epistemológicas, éticas y ontológicas, que se disputan la orientación y legitimación del acto educativo. (Pinto, 2008, p. 92)

Uno de los autores clásicos de la teoría curricular, el británico Stenhouse (1998, p. 29), considera que el currículo "es una tentativa para comunicar los principios y rasgos esenciales de un propósito educativo, de forma tal que permanezca abierto a discusión crítica y pueda ser trasladado efectivamente a la práctica". Siendo esto así, y en tanto 
constructo formativo y cultural intencional, el currículo requiere para su desarrollo unos fundamentos que constituyen la base ideológica -en el sentido amplio del término, que alude a una visión explicativa del mundo y sus fenómenos- desde la cual se conciben y se ejecutan los procesos de enseñanza y de aprendizaje.

Los principios del currículo, entonces, configuran sus dimensiones filosófica (sus referentes en términos del pensamiento y la búsqueda de sentido en relación con la vida social y cultural concreta de los educadores y los educandos), epistemológica (cómo se explica el conocimiento, su producción y su aprendizaje) y pedagógica (cómo se concibe en la teoría y la praxis el hecho educativo y la mediación pedagógica). Siguiendo a Pinto (2012, p. 60), consideramos que estos principios actúan de modo permanente en la vida curricular, y están presentes en la "mirada formativa" que impregna cada experiencia de desarrollo del currículo llevada adelante por los docentes, o dicho en otros términos, se develan en el "proceso de construcción de sujetos, de lenguajes, de acciones y de mundos" que supone la enseñanza. Más específicamente, estos criterios también pueden asociarse a elementos como "la selección/priorización de objetivos y de contenidos", "la selección/organización de las estrategias de enseñanza y aprendizaje", y a las "decisiones sobre los criterios, modalidades e instrumentos de evaluación de los aprendizajes" (Pinto, 2008, p. 118).

\section{EI pensamiento pedagógico latinoamericano en las construc- ciones y disputas curriculares}

Nuestro derecho a pensar como latinoamericanos y latinoamericanas "es ni más ni menos, que la expresión de nuestra voluntad de ser nosotros mismos frente a los otros, en primer lugar, y frente a nosotros mismos como consecuencia de lo anterior" (Mora, 2006, p. 21). Esta idea ocupa un lugar central en nuestra definición del pensamiento latinoamericano y su perspectiva pedagógica como categoría de análisis en este ensayo, entendiendo que esta ofrece un camino de construcción del discurso y de la praxis curricular, que hoy se encuentra prácticamente ausente en los espacios de formación docente en la UNA.

Para sustentar teóricamente nuestras reflexiones, tomamos como referentes al filósofo argentino Arturo Roig (2009, 2011), al filósofo chileno Zemelman (2005) y las contribuciones del propio Pinto, a las 
que ya hemos hecho referencia. No pretendemos agotar aquí el tema ni la caracterización del pensamiento latinoamericano, solamente nos interesa detallar algunos puntos generales para su comprensión.

Para Roig (2011), uno de los principales elementos constituyentes del pensamiento latinoamericano -y de una filosofía nuestra- es la búsqueda del a priori antropológico, o dicho en otros términos:

[el] preguntar por los modos de objetivación mediante los cuales los grupos humanos nuestros han organizado y realizado su vida social, así como su cultura material y simbólica [cuyo estudio] nos abre a un mundo conflictivo, atravesado de contradicciones, dentro del marco de una historia compartida (...) en la que nunca faltaron ideales de humanización. (p. 239)

Este ejercicio filosófico al que alude Roig (2009) no es otra cosa sino el asumir la actitud ontológica de ponernos a nosotros mismos como valiosos, en tanto sujetos y pueblos diversos, lo que supone un acto de impugnación de las fuertes raíces coloniales y eurocéntricas propias del discurso filosófico y del pensamiento Occidental moderno, que permean, a su vez, el discurso educativo, pedagógico y curricular dominante. La diversidad, como oposición a lo homogéneo, a los universales impuestos como normas únicas del ser y del saber, "es el lugar inevitable desde el cual preguntamos y respondemos por el nosotros" (p. 21) latinoamericano. En esa medida, y de acuerdo con lo que propone el intelectual argentino, el pensamiento latinoamericano y sus expresiones en el ámbito de la pedagogía no podrían tener otro signo que no sea el de la transformación de una condición opresora histórica y culturalmente construida, por lo que se trataría de un "saber de liberación, que excede, sin duda, a la filosofía misma, pero cuyas bases teóricas están dadas en ella" (Roig, 2009, p. 17).

A partir de esta clave de liberación, podemos vislumbrar miradas sobre la realidad y su potencial de cambio que acompañan y nutren el filosofar de ese sujeto latinoamericano -y nos aventuramos a precisar: del sujeto docente latinoamericano- que asume el pensar propio: en primer lugar, su mirada ectópica, esto es, su capacidad de "reformular un proyecto identitario, con una abierta actitud dialéctica, (...) abierto a los aires de una mundialización en que la humanidad no aparezca dividida mediante las dicotomías con las que nos hemos regido y nos 
han medido" (Roig, 2011, p. 241). En segundo lugar, su mirada utópica, la que apunta a las ideas reguladoras del horizonte de futuro, a "las palabras-símbolo con las que los sectores emergentes han acuñado ilusiones y sus exigencias de reconocimiento y dignidad" (Roig, 2011, p. 242). Y finalmente, la mirada neotópica, la de "los modos posibles y deseables de convivencia humana" que incorporan la riqueza de los "infinitos universos discursivos del quichua, del aymara, del castellano, del mapudungu, del inglés caribeño, del azteca, del portugués, el maya, el créole haitiano, el sranontongo de Surinam, el holandés colonial y tantos otros, con todos sus discursos, verbales o escritos" (Roig, 2011, p. 243).

Identidad y diálogo, construcción de narrativas emancipadoras e inclusivas de la diversidad cultural y el pluralismo, se nos presentan como dinámicas constitutivas del pensamiento latinoamericano, cuya incorporación al discurso y la práctica curricular consideramos como ética y pedagógicamente necesarias. A esto tendríamos que añadir la actitud crítica frente a los mecanismos de producción y organización del conocimiento -y en particular, del conocimiento legitimado-, como condición de posibilidad de ser sujetos, lo que resulta de vital importancia en el campo de la educación y el currículo. Al respecto, vale destacar aquí la aguda observación de Zemelman (2005):

Parece que el conjunto de conceptos en que se ha ido cristalizando la acumulación de las ciencias sociales, incluyendo también las modalidades que asume la argumentación dominante, está implicando una predeterminación de los espacios de posibilidades del sujeto; en otras palabras, que nos estamos confrontando con un conocimiento construido, de tal modo que autoriza la presencia de un solo tipo de sujeto y, en consecuencia, una limitación en las posibilidades de intervención sobre la realidad que nos circunda. ¿El conocimiento dominante, en efecto, ofrece espacios de posibilidades a todos los sujetos? (p. 85)

Una organización curricular y una práctica de la docencia pensadas ambas desde nuestras necesidades y aspiraciones como latinoamericanos, tendrían que dar una respuesta pedagógica efectiva a la pregunta de Zemelman, que cuestiona la naturaleza y finalidades de las políticas curriculares y educativas, en general, en nuestros países. 
Ahora bien, si partimos de una concepción de la pedagogía en la que se considera su enfoque como indagación y reflexión continua sobre el hecho educativo, que lo describe "y que busca relaciones con otros fenómenos propios de la cultura escolar, que sistematiza sus descubrimientos, que indaga los factores que causa esos fenómenos" (Ordóñez, 2009 , p. 231); y si, además, profundizamos esta conceptualización retomando los aportes freiríamos a la pedagogía crítica $^{3}$, y la entendemos también como compromiso ético, intelectual y cultural del educador en su tarea irrenunciable de humanización, de acompañamiento del educando en su proceso de construcción como sujeto y de ser siempre más -en suma, de su liberación- (Freire, 2002), debemos concluir, entonces, que la pedagogía involucra todas las dimensiones, ejercicios filosóficos y miradas que son propias del pensarnos y construirnos a nosotros mismos desde América Latina.

Así, una reflexión crítica sobre la educación y una práctica pedagógica emancipadora, por un lado, y pensamiento latinoamericano, por el otro, constituyen un binomio desde el cual es posible abordar el dilema que señala Zemelman sobre el conocimiento, la dominación y la diversidad propia de lo humano, sea desde el espacio áulico, sea desde el diseño curricular. De tal suerte, una pedagogía que hunde sus raíces filosóficas, epistemológicas y metodológicas en el pensamiento y la cultura latinoamericanas, está mucho más cerca de precisar respuestas sobre las finalidades de la educación y sobre el ideal de formación docente al que se debería aspirar, según las demandas sociales y las realidades históricamente construidas de nuestros contextos.

En esta línea, hay tres campos del saber que pueden enriquecer la búsqueda de esas respuestas desde la acción pedagógica crítica y liberadora, que entendemos como aquella en la que el método -"la forma exterior y materializada en actos"- es consecuente con la intencionalidad liberadora -"la propiedad fundamental de la conciencia"-, es decir, el camino para estar con el mundo, que guía al educador en el ejercicio

3 Proponer la pedagogía crítica como base para la formación de docentes, en particular, en el contexto universitario, tiene implicaciones en varios órdenes: acaso el más importantes de ellos, el ubicar la transformación de las realidades educativas como intencionalidad intrínseca de la docencia. Vale recordar aquí, como claramente lo explica McLaren (2001), que la pedagogía crítica es "una manera de reflexionar sobre, negociar con y transformar la relación existente entre la enseñanza en el aula, la producción de conocimiento, las estructuras institucionales de la escuela, y las relaciones sociales y materiales pertenecientes a la comunidad" (p. 51), incluso en el ámbito mayor del Estado-nación y las relaciones en el sistema-mundo. 
de su docencia (Freire, 2002, p. 66). Uno de estos campos corresponde al de la filosofía latinoamericana, y dentro de este, la corriente de la filosofía de la liberación, que aporta tres elementos atinentes a la construcción de una perspectiva pedagógica con referentes en nuestra América: "la comprensión del ser latinoamericano como un sujeto histórico y cultural", el movimiento de humanización que adquiere sentido en "su praxis de conocer y transformar el mundo" (Pinto, 2012, p. 38), y el reconocimiento del sujeto como ser inacabado, que demanda el desarrollo permanente de su pensamiento crítico, y abre, así, un espacio preferencial para la acción educativa. Las ciencias sociales, por su parte, como segundo campo, incorporan "la concepción de la realidad latinoamericana como problema cognoscible o posible de conocer por los actores que la viven", situación que potencia la conciencia crítica transformadora "que surge de la práctica de investigar la realidad y poder actuar sobre ella" (Pinto, 2012, p. 41). Y por último, el campo de la pedagogía crítica, con su multiplicidad de tendencias teóricas, sociales, políticas y culturales, enriquece la perspectiva pedagógica latinoamericana al postular una educación liberadora, que "contribuya a un desarrollo humano más humano y más igualitario, que favorezca el pensamiento crítico y la comunicación transformativa de nuestras individualidades y de nuestras vivencias colectivas" (Pinto, 2012, p. 43).

Siempre dentro del enfoque esbozado al inicio del ensayo, es decir, el de las relaciones entre currículo e ideología, el posicionamiento crítico que se deriva de la perspectiva pedagógica latinoamericana nos permite señalar varios puntos de atención sobre la formación de docentes en la región. Así, encontramos que los rasgos de dependencia y contradicción propios de nuestras sociedades y de su conformación histórica, tienen su correlato en el ámbito de la cultura académica, por lo tanto, en las políticas y contenidos curriculares. A esto nos referiremos a continuación.

Un primer punto tiene que ver con la subordinación filosófica del contenido cultural del currículo de los programas de formación de docentes, en los que predominan el énfasis "erudito-etnocentrista de sus enfoques", las "matrices epistemológicas no latinoamericanas" y la visión "funcional-estructuralista" del docente como "transmisor de saberes (...) que se concretan en el quehacer del aula". Es decir, en la formación de los docentes se partiría de situaciones ya construidas desde referentes filosóficos, axiológicos y culturales ajenos a lo latinoamericano, y donde "los valores y las competencias profesionalizantes aparecen como códigos o 
significaciones socioculturales sobredeterminados, ya seleccionados y organizados", con el agravante de que la perspectiva docente crítica y la necesidad de formar "un profesor contextualizador y generador de autonomía formativa simplemente es desconocida, ignorada o impedida de ser desarrollada institucionalmente en los Centros de Formación Superior del Profesorado Latinoamericano" (Pinto, 2001, pp. 6-7).

Un segundo punto nos remite al problema de la reducción del campo de la producción curricular, bajo la acción de dos procesos: uno, el del predominio de la racionalidad adaptativa o reproductora (la lógica técnico-instrumental), "que privilegia la secuenciación de los objetivos y los contenidos unidisciplinarios" del currículo y "la permanencia de un procedimiento evaluativo que procura calificar logros, o conductas y resultados de programación, e intenta medir con ello los procesos formativos mismos" (Pinto, 2008, p. 56); y el otro, los condicionamientos que, desde la década de 1990, imponen las reformas educativas impulsadas por organismos como el Banco Mundial, con la pretensión -por lo menos enunciativa- de apoyar "los procesos de modernización política del Estado y el aumento del valor agregado de la producción económica" (Pinto, 2008, p. 66). Ambos procesos han redundado en la creación de una suerte de estratificación del diseño de políticas curriculares, que refleja, a su vez, una concepción de la educación permeada por factores de poder. Se distinguen aquí tres estructuras: la primera, tecnocrática, centraliza las funciones de "orientar, diseñar, normar y evaluar el cambio educativo-curricular" en cada país; la segunda, es la estructura institucional integrada por directivos-docentes y docentes-técnicos, quienes generan y aprueban "proyectos curriculares actualizados y pertinentes a la doctrina educativa dominante" y "planes y programas de estudio" adecuados a las normas curriculares impuestas a nivel superior; y por último, la estructura "operativa del currículo en el salón de clases" (Pinto, 2008, p. 67), donde los márgenes de acción del docente van a estar condicionados a la selección de contenidos, procesos y prácticas de los programas y proyectos en que se le inscribe, y a su capacidad de implementar innovaciones dentro del estrecho margen que tolera el sistema.

El tercer punto crítico de atención es el de la subordinación del marco político de la formación, lo que quiere decir que la concepción política del docente, por lo menos desde la perspectiva oficial, prioriza la profesionalización de la docencia pero en un sentido particular: 
es la idea de preparar "en un saber hacer instrumental: enseñar para que el otro aprenda" (Pinto, 2001, p. 8). Con esto, intentamos destacar la inclinación formativa hacia un adiestramiento en las cuestiones didácticas, antes que en una formación pedagógica mucho más integral, crítica y situada en la realidad latinoamericana. Según Pinto (2008, p. 51), ese sesgo deriva en el perfilamiento de un profesional "con una relativa autonomía pedagógica", ya que ha sido formado "con un profundo sentido ético-social de respeto a lo establecido, a lo normado, a lo institucionalizado, donde su competencia reconocida y legitimada socialmente, es hacer funcional la cultura escolar-curricular a los requerimientos de adaptación y de conservación", que demanda la cultura nacional hegemónica.

Finalmente, la subordinación de lo académico a lo administrativo en la gestión de la formación nos confronta con fenómeno en el que inciden las cuestiones vinculadas con el poder y el control social de la profesión docente, y que se evidencia en la falta de fuentes de financiamiento y subsidio público para la educación y la formación (intensificada bajo el modelo económico neoliberal); el peso de lo burocrático sobre lo académico (la carga horaria del académico universitario se recarga en la docencia); la poca investigación y producción intelectual de los docentes -relacionado con el poco tiempo disponible para estas tareas-; y el predominio de la lógica técnico/instrumental en la elaboración curricular. Además, en esta subordinación se expresa una racionalidad basada en "la centralidad del poder decisional y la concentración del control ideológico y social de la autonomía del otro", una racionalidad autoritaria y verticalista, que limita las condiciones para que, desde la instancia educativa, se haga sentir la democracia como "posibilidad de la diversidad cultural y social y como organización de la horizontalidad de las relaciones sociales y políticas" (Pinto, 2008, p. 53).

Esta conjunción de factores incide en el hecho de que en América Latina se desarrolle "una práctica pedagógica contradictoria y conservadora", enraizada "en los docentes formadores y en las instancias técnico-directivas que toman las decisiones curriculares" (Pinto, 2001, p. 12); pero, a la vez, visto el problema con ojos de esperanza, también configuran un campo educativo y cultural de acción donde el pensamiento y la perspectiva pedagógica latinoamericana están llamados a incidir y a generar procesos de discusión y cambio. 


\section{A manera de conclusión: ser docentes situados en América Latina}

Si el actual estado de cosas en materia de pensamiento, elaboración y producción del currículo en la educación latinoamericana señala, de manera inobjetable, la necesidad de una ruptura con los marcos tradicionales (técnico-instrumentales) que orientan este campo intelectual y cultural, la vía para lograr esa superación pasa por asumir nuevos enfoques, entre estos, el "epistemológico socioconstruccionista, que concibe el conocimiento como un sentido/significado relacional entre el sujeto y su entorno sociocultural y físico" (Guzmán y Pinto, 2004, p. 126).

La concepción del currículo -y de su proceso de construcción- de Guzmán y Pinto va más allá de la prescripción de contenidos y saberes por parte de las autoridades educativas de un centro académico, de una agencia o ministerio estatal, en cambio; por el contrario, lo consideran como el resultado de una experiencia de acción y comunicación crítica transformadora de los sujetos protagonistas de la comunidad educativa. El proyecto curricular, entonces, "es el producto colectivo institucional de una práctica social de búsqueda de sentidos y de significados para una comunidad escolar situada" (Guzmán y Pinto, 2004, p. 126).

De esta reflexión emerge la idea o noción de docente latinoamericano situado, como horizonte formativo y pedagógico hacia el cual avanzar si se asume el compromiso de transformación de la educación regional, especialmente, de los discursos curriculares dominantes. El ser educador o docente situado en América Latina supone "conocer y dominar los saberes profesionales que le permitan actuar como formador integral de los educandos con los cuales le toca interactuar"; y además, que interioriza los fundamentos y las prácticas de una identidad docente que "problematiza la opción unidimensional y sistémica [de la educación] que se reproduce oficialmente en las instituciones y organizaciones educacionales" (Pinto, 2012, p. 18) de nuestra región.

En la formación del docente latinoamericano situado, los saberes pedagógicos son vistos en un sentido integral, no fragmentado ni instrumental, por lo que adquieren protagonismo como núcleo central que anima la formación de un educador capaz de articular, con autonomía de criterio y contextualizadamente, todos aquellos aspectos involucrados en la toma de decisiones curriculares, didácticas y éticas propias de los procesos de enseñanza y aprendizaje (Pinto, 2012, pp. 119-125). Asimismo, las competencias se definen como conocimientos 
y prácticas educativas críticas -a diferencia de la connotación que tiene el concepto, por ejemplo, en el llamado Espacio Común Europeo-, e involucran cuatro ámbitos: el de la identidad docente (cómo se posiciona el educador "en la vida social y cultural nacional", y en qué medida actúa como "promotor de la justicia social y la ética liberadora"); el de las competencias epistemológicas (para "convertirse en "un gestor crítico del conocimiento enseñado/construido con los educandos"); el de la comunicación (en torno a una pedagogía del diálogo); y finalmente, el de las competencias transformativas de la práctica docente, relacionadas con la innovación y re-construcción de los saberes (teorías, modelos pedagógicos, conocimientos disciplinares), las metodologías, las estrategias de enseñanza y, en general, las formas de mediación que contribuyan a construir una cultura educativa de la participación más que de la prescripción de normas y contenidos propios del conocimiento oficial (Pinto, 2012, pp. 136-139).

Estas condiciones sintetizan el perfil del docente latinoamericano situado: un educador debidamente formado y competente en su área profesional; capaz de interpretar cultural e históricamente su entorno de acción y las necesidades y expectativas de las personas que participan del aprendizaje; por último, con destrezas para la gestión del conocimiento, del currículum y de las estrategias pedagógicas y didácticas más apropiadas. En términos de la formación de docentes con este perfil, el desafío radica en lograr que el futuro educador o educadora logre "seleccionar y trasmitir contextualizadamente los conceptos o definiciones o conocimientos que estén más próximos a la capacidad de comprensión y de aplicación de sus eventuales educandos; esto debe traducirse en las planificaciones formativas que elabore, para atraer la atención y la motivación de esos educandos" (Pinto, 2012, p. 119).

La intencionalidad que me animó en la redacción de este texto fue ensayar un abordaje de la construcción cultural del currículo desde América Latina porque, como bien lo expresa el Dr. Arnoldo Mora Rodríguez (2006, p. 27), en medio del actual proceso de globalización nunca como ahora la reflexión sobre nuestro pensamiento, nuestra cultura y nuestra historia se nos presentan con tanta urgencia para dirimir un viejo dilema: “¿Lograremos por fin ser nosotros mismos, decir una palabra que sea realmente nuestra en la historia de la humanidad?" El filósofo y educador cubano Pablo Guadarrama (2001, p. 265) llama misión pedagógica a esta tarea de pensar y pensarnos desde nuestras 
realidades nacionales y regionales, una labor que "hay que desarrollarla en primer lugar desde dentro del mundo de la docencia universitaria y las instituciones culturales", y que resulta de la mayor importancia dadas las condiciones adversas que, por desgracia, enfrenta el pensamiento latinoamericano para posicionarse en el quehacer de nuestros centros de educación superior. Ojalá las reflexiones y propuestas desarrolladas en este ensayo, contribuyan a despertar nuevas inquietudes en los lectores y a plantearnos el desafío intelectual y pedagógico de seguir indagando y proponiendo ideas que nos permitan, en nuestras universidades, dar un giro latinoamericanista a la formación docente. Nada nos es más necesario.

\section{Referencias bibliográficas}

Acosta, D. et al (2010). El currículo socio-crítico: una propuesta pedagógica transformadora. Revista Escenarios, (8). Pp. 33-47.

Apple, M. (2008). Ideología y currículo. Madrid: Ediciones Akal.

Barrón, M. (2009). Docencia universitaria y competencias didácticas. Perfiles Educativos, 31 (125). Pp. 77-87.

Becerra, R. y Moya, A. (2009). Pedagogía y didáctica crítica. Hacia la construcción de una visión latinoamericana. Revista de Investigación Educativa, 2 (1). Pp. 13-24.

Beltrán, F. (2010). Política, poder y control del currículum, en: Gimeno Sacristán, J. (comp.). Saberes e incertidumbres sobre el currículo. Madrid: Ediciones Morata.

Cuevas, R. (2008). Universidad, cultura y democracia en América Latina: la era neoliberal. Cuadernos Americanos: Nueva época. 3 (125). Pp. 23-38.

Duhalde, M. (2008). Pedagogía crítica y formación docente. En: Paulo Freire. Contribuciones para la pedagogía. Godotti, M. et al. (comp.). Buenos Aires: CLACSO. Disponible en: http://bibliotecavirtual.clacso.org.ar/ar/libros/campus/freire/20Duhal.pdf

Duhalde, M. y Cardelli, J. (2001). Formación docente en América Latina. Una perspectiva político-pedagógica. Cuadernos de Pedagogía, (308). Pp. 38-43.

Fernández, N. y Coppola, N. (2008). La evaluación de la docencia universitaria en Argentina. Situación, problemas y perspectivas, $R e$ vista Iberoamericana de Evaluación Educativa. 1 (3). Pp. 97 -123. 
Freire, P. (2002). Pedagogía del oprimido. México, D.F.: Siglo XXI Editores.

Gimeno-Sacristán, J. (comp.) (2010). Saberes e incertidumbres sobre el currículo. Madrid: Ediciones Morata.

González, V. y González, R. (2008). Competencias genéricas y formación profesional: un análisis desde la docencia universitaria. Revista Iberoamericana de Educación. (47). Pp. 185-209.

Guadarrama, P. (2001). Humanismo en el pensamiento latinoamericano. La Habana: Editorial de Ciencias Sociales.

Guzmán, M. y Pinto, R. (2004). Ruptura epistemológica en el saber pedagógico: la resignificación del episteme curricular. Theoria, 13. Pp. 121-131.

Lucarelli, E. (2004). Prácticas innovadoras en la formación del docente universitario, Educação, 27 (3). Pp. 503-524.

McLaren, P. (2001). Che Guevara, Paulo Freire y la pedagogía de la revolución. México D.F.: Siglo XXI Editores.

Mora, R. (2004). Perspectivas teóricas curriculares latinoamericanas, Revista Psicogente, 12. Pp. 133-147.

Mora, A. (2006). La filosofía latinoamericana. Introducción histórica. San José, C.R.: EUNED.

Olmos, O. (2008). La pedagogía crítica y la interdisciplinariedad en la formación del docente. Caso venezolano. Sapiens, 9 (1). Pp. $155-177$.

Ordóñez, J. (2009). Introducción a la pedagogía. San José, C.R.: EUNED.

Pareskeva, J. (2008). El currículo como práctica de significaciones, en Angulo, J. (comp.). Democracia, educación y participación en las instituciones educativas. Sevilla: Cooperación Educativa. En: http://www.quadernsdigitals.net/datos/hemeroteca/r_ 7/ nr_498/a_6791/6791.pdf

Pestana, N. (2003). Nuevas visiones sobre la formación: el caso de la reestructuración de un programa de actualización de los profesores universitarios. Educere, 6 (21). Pp. 46-53.

Pinto, R. (2008). El currículo crítico. Una pedagogía transformativa para la educación latinoamericana. Santiago de Chile: Ediciones Universidad Católica de Chile.

Pinto, R. (2009). La necesidad de un nuevo paradigma curricular para una época compleja. Revista Posgrado y Sociedad. 9 (1). Pp. 1-25. 
Pinto, R. (2012). Principios filosóficos y epistemológicos del ser docente. San José, C.R.: Coordinación Educativa y Cultura Centroamericana / SICA.

Roig, A. (2009). Teoría y crítica del pensamiento latinoamericano. Buenos Aires: Una Ventana.

Roig, A. (2011). Rostro y filosofía de nuestra América. Buenos Aires: Una Ventana.

Saxe, J. (2001). Globalización, poder y educación pública. Economía y Sociedad. (15). Pp. 83-99.

Solano Muñoz, E. (2010). La crisis contemporánea de la financiación de la educación superior pública en Costa Rica: un eslabón más de la estrategia neoliberal. Revista Electrónica Actualidades Investigativas en Educación, 10. Pp. 1-20.

Soto, D. (2009). El profesor universitario de América Latina: hacia una responsabilidad ética, científica y social. Revista de Historia de la Educación Latinoamericana, (3). Pp. 166-188.

Sousa, B. (2006). Renovar la teoría crítica y reinventar la emancipación social. Buenos Aires: CLACSO.

Stenhouse, L. (1998). Investigación y desarrollo del curriculum. Madrid: Ediciones Morata.

Vain, P. (1998). La evaluación de la docencia universitaria: un problema complejo. Buenos Aires: Serie Estudios - CONEAU.

Vargas Rodríguez, E. (2008). El reto de los años noventa: sus logros, dificultades y sueños en un contexto de crisis presupuestaria para quienes no éramos prioridad en la universidad. Revista Electrónica Educare. XII (1). Pp. 159-165.

Vega-Carballo et al. (2010). Banco Mundial y el (des)financiamiento de la Educación Superior Pública. Heredia, C.R.: Universidad Nacional - Facultad de Ciencias Sociales.

Zemelman, H. (2005). Voluntad de conocer. El sujeto y su pensamiento en el paradigma crítico. México D.F.: Anthropos Editorial / Centro de Investigaciones Humanísticas de la Universidad Autónoma de Chiapas. 